\title{
Imitar y fabricar. Las naturalezaculturas de las agriculturas guaraní, colona y agroecológica
}

Imitation and manufacturing. The nature-cultures of the Guaraní, colonist and agroecological agricultures

\author{
Gabriela Schiavoni $^{*}$ \\ * Consejo Nacional de Investigaciones Científicas y Técnicas - Posadas, \\ Misiones, Argentina \\ gacha@arnet.com.ar \\ https://orcid.org/0000-0001-5931-2875
}




\title{
Resumen
}

Considerando la imitación y la fabricación como procedimientos de vinculación con la naturaleza, nuestro artículo describe las prácticas agrícolas de las poblaciones locales y de los agricultores inmigrantes, en la provincia de Misiones (Argentina). El énfasis en los procedimientos permite establecer continuidades, y también fricciones, entre grupos juzgados como antagónicos. Descalificadas por el racionalismo, la imitación y la mímesis son valoradas aquí en términos de un enfoque materialista de la significación que discute la primacía otorgada a las representaciones simbólicas.

Palabras clave: materialidad; representaciones; técnicas; mímesis.

\begin{abstract}
Considering imitation and manufacturing as procedures of connection with nature, our article describes the agricultural practices of local populations and immigrant farmers in the province of Misiones (Argentina). The emphasis upon the procedures allows to establish continuities, and also frictions, between groups judged as antagonistic. Disqualified by rationalism, imitation and mimesis are valued here in terms of a materialist approach to meaning that discusses the primacy given to symbolic representations.
\end{abstract}

Keywords: materiality; representation; technique; mimetic. 


\section{Introducción}

Nociones desacreditadas, tales como las de imitación y participación, son rescatadas por los enfoques materialistas que ponen en cuestión la idea de representación. ${ }^{1}$ Siguiendo un procedimiento análogo al de las ciencias naturales, la labor del científico social consistiría en examinar flujos de fuerzas regidos por la imitación, el contagio y las semejanzas. ${ }^{2}$

La naturalización, considerada una trampa u ocultamiento por el constructivismo, adquiere aquí un sentido positivo. En efecto, naturalizar es remitir a un orden en el que los significados no están filiados exclusivamente a representaciones simbólicas, sino que se establecen en interacción con el ambiente, asociando por contigüidad, o mediante parecidos icónicos.

Así, los Runa de Ecuador, relatan por imitación, recreando los ruidos y visiones de la presa durante la cacería (Kohn, 2013). Este "memorando perceptual" (Carneiro da Cunha, 2009) es un formato de transcripción distinto de un discurso de autoridad que procede elaborando experiencias en bruto.

Una perspectiva de este tipo quita exclusividad a lo humano, tomando como eje las relaciones entre especies (etnografía multiespecie; cf. Kirksey y Helmreich, 2010). La domesticación deviene un proceso emergente de cohabitación, en el que las transformaciones son engendradas no solo a través de un diseño mental. Los ambientes dejan de ser un fondo homogéneo, estático, para un sujeto focalizado, y se vuelven complejas "ecologías de seres", medios dinámicos en constante modelaje y remodelaje (Van Dooren; Kirksey; Münster, 2016), cuyo ensamblaje se efectúa por contigüidad, mediante series de identificaciones sucesivas, semejantes a las descriptas por Lévy-Bruhl (1947) y retomadas por Lévi-Strauss (1962, p. 297), a propósito del sacrificio.

La noción de naturalezaculturas describe este proceder que denominamos analógico porque asocia sin el recurso a un principio externo, guiándose por parecidos, simbiosis y contagios entre humanos y no humanos. Desde este

1 Los significados no constituyen un mundo aparte de la materia ni una prerrogativa humana que se procesa en la mente como operación racional. Los adquirimos por inmersión en el ambiente, a través de la relación con otros organismos.

2 En tanto proceder de la materia subrepresentativa, la imitación es la propagación de un flujo, que exhibe puntos de contacto con la acción por contagio y la acción por semejanza, identificadas como modos de hacer de la magia simpática. 
ángulo, la agricultura se asemeja a la acción indirecta negativa de Haudricourt (1962) más que a un mecanismo de fabricación (Larrere, 2002). La técnica deja de ser el producto exclusivo de una operación intelectual para volverse un fenómeno amplio, basado en la cohabitación entre organismos.

El hecho de colocar el énfasis en los modos de obrar antes que en los caracteres, invita a repensar los esquemas dualistas que han mapeado los vínculos que mantienen con el ambiente las poblaciones de guaraníes y colonos en la provincia de Misiones, en el nordeste de Argentina (Cebolla Badie, 2000; Ferrero 2009; Wilde, 2008). Así, nos proponemos entrelazar formas de vinculación con la naturaleza juzgadas como contrapuestas, contemplando el aprendizaje ambiental de los colonos junto a las poblaciones indígenas, y sopesando el hecho que la agroecología remite en la provincia a ciertos devenires colonos. En efecto, en las últimas décadas del siglo XX, en la franja costera del río Paraná, colonos suizos y teuto brasileros reaccionan frente a la pérdida de fertilidad del suelo y al monocultivo forestal, enunciando como tecnología un "plan que imita la naturaleza", identificándose -en algunas versiones- con una "etnoecología" guaraní.

La concepción de la agricultura como imitación de la naturaleza se mantiene en fricción ${ }^{3}$ con la lógica estatal de fabricación. Así, los funcionarios que recorren el recién creado territorio nacional de Misiones, a fines del siglo XIX, subrayan como anómala la simbiosis del monte y el rozado (tierra desmontada para uso agrícola).

Si bien el enfoque multiespecie ha sido desarrollado en conexión con el estudio de sociedades indígenas, nuestro trabajo etnográfico en los frentes pioneros nos permitió apreciar las relaciones complejas que entablan con el ambiente los pequeños agricultores, otorgando pertinencia a esta perspectiva también para el caso de las sociedades campesinas no indígenas. En efecto, el habitar del ocupante imita el modo silvestre de expansión. A semejanza de las colonias vegetales, las colonias de humanos fruto de la ocupación espontánea, se propagan por multiplicación rizomática, fundadas en un compañerismo interespecífico. La familiarización con los productores ocupantes

3 En el sentido que le otorga Tsing (2005), es decir, interconexiones toscas y cambiantes, a través de la diferencia. 
de los asentamientos no planificados de las tierras públicas vacantes de Misiones favoreció nuestra comprensión del carácter híbrido -naturalcultural- de la agricultura. Los datos provenientes del trabajo de campo realizado durante las dos últimas décadas en los frentes pioneros del nordeste provincial (departamentos San Pedro y Gral. Belgrano) conforman la principal fuente de datos de este artículo.

A su vez, el poblamiento dirigido de la colonización de Misiones no estuvo filiado completamente al Estado y a las empresas. La instalación agrícola de los 'colonos de la selva' se desarrolló en simbiosis con el ambiente y con la población nativa. Esta participación se escindió luego en un vínculo de oposición y lucha, tantas veces evocado por los relatos de los inmigrantes pioneros de la zona costera del río Paraná (departamentos Gral. San Martín y Montecarlo). Las memorias de estos colonos constituyen la segunda fuente de datos que utilizaremos. ${ }^{4}$

\section{Imitaciones}

Geertz (1970, p. 16, traducción propia) califica las prácticas de roza y quema en Indonesia como "una astuta imitación del paisaje natural", "una agricultura que remeda la diversidad generalizada de la selva a la que reemplaza temporariamente". En el caso de la agricultura de coivara ${ }^{5}$ en Misiones, no se trata de la imitación de productos sino de un proceder conjunto de humanos y vegetales. Esta simbiosis se expresa en la 'capuera', formación que resultó extraña a los viajeros y comisionados estatales que recorren Misiones a fines del siglo XIX. El mantenimiento del término nativo en las crónicas oficiales es un indicio de la dificultad para traducir la inscripción de la agricultura nativa en el proceder de la naturaleza, favoreciendo la cohabitación del monte y los espacios domesticados.

4 Los títulos que componen este corpus han sido editados mayormente por la Universidad Nacional de Misiones. Incluye las obras de Weyreuter (1992); Naujorks (1995); G. Müller (1995); Culmey (1998); y las compilaciones realizadas por Gallero $(2008,2014)$.

5 Tierras de cultivo abiertas en el monte mediante la quema de troncos, que luego vuelven a ser cubiertas por selva. 
El agrimensor que mide el territorio a fines del siglo XIX, anota:

He usado la palabra capoera. Ella designa un viejo rozado en el que se ha dejado de plantar con el designio de dejar descansar la tierra. Esas capoeras que conservan casi siempre los grandes troncos de los árboles volteados para formar el rozado, se cubren, a la vuelta de poco tiempo, de una vegetación tupida, aunque salvaje, por lo cual hay que rozar nuevamente cuando se quiere volver a plantar. (Queirel, 1897, p. 402).

Observando las operaciones agrícolas en las proximidades de la localidad misionera de San Javier, Ambrosetti (1892, p. 33) -fundador de los estudios etnográficos en Argentina-relata: "Primero plantan maíz [...] y después de vuelto a rozar y quemar, plantan el poroto; después del poroto abandonan el rozado, que queda llamándose capuera y hacen otro".

Un naturalista comisionado por el Estado nacional para efectuar el reconocimiento de Misiones, da cuenta de la agricultura nativa en términos análogos:

Los naturales acostumbrados a rozar, ejecutan esta labor con relativa facilidad [...] Si se abandona el sitio, se produce allí un enmarañamiento tal de cañas y malezas de toda clase, después de uno o dos años, que se hace impenetrable. A esto llaman los brasileros capoeira. (Burmeister, 1899, p. 36).

También la caracterización del especialista enviado por el Ministerio de Agricultura de la Nación, se establece en consonancia con las opiniones que venimos reseñando. Afirma que:

Se entiende por rozar en el monte, abrir un claro dentro de él para dedicarlo a la siembra o a la plantación [...] Cuando un rozado de estos se abandona no tarda mucho en ser cubierto por un espeso matorral y entonces se transforma en los que se llama capoera. (Yssouribehere, 1904, p. 99).

\section{Devenires humano-vegetales: "lo que viene [crece] solo"}

Un fragmento del diario del explorador de yerbales Adán Lucchesi, incluido en las Cartas Misioneras de Peyret describe la mímesis entre el proceder humano 
y el proceder de la naturaleza a propósito de una capuera. Así, en el recorrido que realizan desde Iguazú a Campo Eré:

[los expedicionarios] pueden observar un rozado de cuatro o cinco cuadras de forma redonda, que les hace pensar en alguna antigua capuera; pero dándose a estudiar más minuciosamente la vegetación inferior, no pueden observar señal de hacha o fuego en parte alguna. Creen entonces algunos que el rozado puede ser obra de algún fuerte remolino de viento [...] pero otros sostienen que es obra de gente, si bien de mucho tiempo atrás. (Peyret, 1881, p. 206).

En un estudio reciente realizado con pequeños agricultores en Misiones, el autor refiere que la pregunta acerca de las prácticas que fomentan el avance del monte sobre el campo "resultó graciosa a la mayoría de los informantes". Las respuestas variaron en torno a que "el monte avanza solito", o "sólo sacando la vaca nomás". Se trata, en efecto, de una metamorfosis ejecutada por las propias plantas:

Cualquier planta de los montes, puede ser una planta de Kokú [A. edulis], de pitanga [E. uniflora], de aruera [L. molleoides]. Y viene viniendo toda esa planta, tomando cuenta del campo [...] Encapuera, primero de maderita, y de a poco va engrosando. (Stampella, 2015, p. 130).

En términos botánicos, el devenir vegetal de la capuera se explica así: "Los arbolitos pioneros, especialmente el 'fumo bravo' (Solanum auriculatum) y la chilca (Baccharis dracunculifolia), han creado el ambiente forestal necesario para que puedan germinar y progresar las especies selváticas, que en su juventud son umbrófilas. Al crecer éstas, terminarán por eliminar a los pioneros, que son marcadamente heliófilas, con lo que se habrá llegado al estado de 'capuerón"' (Martínez Crovetto, 1963, p. 195).

La capuera está inserta en una serie de progresión y regresión, reflejada en la acepción múltiple del término, ya sea como chacra abandonada, como chacra en uso o como monte futuro. ${ }^{6}$

6 Tampoco los hanunóo de Filipinas “tienen un término general para agricultura swidden, sino que emplean un conjunto de términos que distinguen estadios de desarrollos de áreas swidden, potenciales, actuales o antiguas" (Conklin, 1954, p. 135, traducción propia). 
En el guaraní colonial que registra Ruiz de Montoya (1639) se menciona que la chacra (cog) que ya no tiene uso agrícola se denomina cocuera y continúa siendo una fuente de recursos. Refiere la existencia de unos porotos denominados cocueriba, porque se dan bien en las chacras abandonadas (Ruiz de Montoya, 1639, p. 98).

Entre las obras de referencia del guaraní contemporáneo, el diccionario de Guasch y Ortiz (1993) no incluye el término capuera, consignando la palabra kokuere para indicar una chacra abandonada. ${ }^{7} \mathrm{~A}$ su vez, el vocabulario de Jover Peralta y Osuna (1950) reporta el sentido de capuera como chacra actual, acepción que también recoge Rengger. ${ }^{8}$

Al traducir el término plantación (cogue) como 'lo que fue pradera', el padre Müller suprime el pasado montaraz del rozado, justificando su interpretación en el hecho que "antes de que se importara el hacha de hierro europea, solían conformarse realizando plantaciones después de quemar la vegetación herbosa en la pradera" (Müller, F., 1989, p. 37).

La acepción de capuera como futuro monte ${ }^{9}$ obtendrá gran difusión a fines del siglo XX, de la mano del movimiento ecologista en la provincia. Finalmente, el diccionario portugués Michaelis (1987, traducción propia), en la entrada capoeira señala el origen tupí del término (caá-puéra), con el significado de "monte ralo de pequeño porte que nace donde se volteó la selva virgen".

La cohabitación de plantas silvestres y cultivadas es ilustrativa de la condición naturalcultural de esta comunidad vegetal. Así, el enviado del Ministerio de Agricultura de la Nación consigna que el cultivo de yerba mate a gran escala se inició con plantas "abandonadas entre el monte y las capoeras altas", mediante la adquisición de chacras poco explotadas de antiguos pobladores de la localidad de San Ignacio (Misiones). Y, continúa: "Varias de esas chacras, es decir, el monte y las capoeras de las mismas, han sido limpiadas a machete,

7 En Crivos et al. (2007, traducción propia) encontramos la siguiente definición: “Las 'capueras', que los Mbya llaman 'kokuere' (aquello que fue usado como chacra o 'kokue') [...] es el nombre dado a esas áreas despejadas, caracterizadas por la presencia de vegetación secundaria, arbustos y pequeños árboles".

8 "En casi todas partes se dejan en pie, entre las chacras (capueras) no cercadas, pequeños bosquecillos (islas) a fin de tener madera" (Rengger, 2010, p. 304). Y, también Cadogan (1990, p. 87): "A nadie se le ocurrirá buscar caballos en mi kokueré -parcela cultivada o en barbecho-".

9 Martínez Crovetto (1963) de acuerdo a la siguiente etimología: kaá: monte /puà: crecer /ra: futuro. 
poniéndose al descubierto no menos de quince mil plantas de yerba mate" (Yssouribehere, 1904, p. 82).

También Niklison, un inspector de trabajo que recorre los establecimientos madereros y yerbateros del Alto Paraná en 1914, documenta la plantación de mandioca en capueras, asociada a la cesión de pequeñas parcelas a los trabajadores para que lleven a cabo cultivos de subsistencia. ${ }^{10}$ En tiempos más recientes, los ocupantes de la frontera agraria de Misiones hacen referencia a la capuera como un espacio silvestre vinculado a lo doméstico a través de la frecuentación de los animales de cría. Así, una agricultora comenta: "la peru [pavo] pone huevos en la capuera". En otro caso, una mujer refiere: "mi chancha blanca cuando sale va a las capueradas y sólo con los perros la traigo".

Una de las raras menciones a la capuera encontrada en las memorias de los colonos de Misiones, es el relato de un inmigrante que cuenta sus experiencias a comienzos del siglo XX: "Y así yo tenía que meterme en las capueras y en la selva para encontrar comida para los animales. Para mí eso no era un problema. Después de todo era yo un hijo de la selva" (Naujorks, 1995, p. 20).

En fricción con este accionar humano de mimetización con la naturaleza, la agricultura de fabricación encarada por el Estado supondrá la ruptura con el monte y con los derechos móviles sobre la tierra, concomitantes del sistema de roza y quema.

Estudiando el fenómeno en Filipinas, en la década de 1950, Conklin (1954) señala que los rozados nuevos sólo excepcionalmente se hacen en el monte virgen, de modo que los campos cultivados continúan las huellas de antiguos barbechos. También el "derecho de capuera", rastro del uso agrícola, conectando a los ocupantes con los espacios -ahora silvestres-, que cultivaron antes, convirtiéndolo en germen de apropiación de la tierra.

En nuestra zona de estudio, el carácter itinerante de la agricultura indígena que imita la naturaleza queda reflejado en ciertas formas de territorialidad, que es menester corregir con el fin de arraigar poblaciones. El comisionado agrícola

10 'Al rozado antiguo cubierto de malezas, se la da el nombre de 'capoeras' [...] la mandioca se planta en las capueras ya que la realización de un rozado en la capuera es más barata que en el monte virgen" (Niklison, 2009, p. 152-153).

11 Se ejerce sobre las parcelas ya utilizadas, en las que tiene prioridad quien las usó antes (Musumeci, 1988, p. 83). 
observa que el incluso el arrendamiento, practicado por la población criolla, reviste en Misiones características móviles, diferentes a la versión pampeana, ya que: "El arrendatario aquí paga un tanto al año por lo que se llama el derecho de 'morada' o por 'fogón' para establecer la vivienda y sembrar un alquer ${ }^{12}$ o dos cuando mucho" (Yssouribehere, 1904, p. 59-60).

La filiación de la naturaleza al trabajo humano supone el uso permanente del suelo, quedando supeditada, en Misiones, al poblamiento con colonos de ultramar. El especialista que venimos citando, lo expresa en estos términos:

El criollo está en evidente desproporción frente al elemento extranjero [...] Siembran por necesidad, pequeñas "rueditas" [...] término con que designa a los pequeños cuadros donde se ven muestras de cultivos indispensables para la subsistencia: maíz, mandioca, batata. (Yssouribehere, 1904, p. 52).13

\section{El proceder humano-vegetal: afinidades y conexiones transversales}

La propagación sin filiación, la multiplicidad que escapa al control humano, caracteriza el proceder de la naturaleza. Las memorias de un colono de Misiones relatan la amenaza constituida por estos devenires vegetales. Escribe:

Nuestro padre tuvo la mala suerte de haber comprado uno de los peores terrenos [...] Allí había yuyos que no existían en otra parte. Por ejemplo, había Backblätter [hoja para cocinar; Canna paniculata]. No tienen en balde esa denominación, pues las hojas se colocaban en los moldes para hornear pan como sustituto de grasa [...] Después de quemar un desbosque se llenaba la tierra de esa maleza. Si no se arrancaban las plantitas chicas, se perdía la batalla [...] Nuestros cultivos se ahogaban en ese mar de hojas. (Müller, G., 1995, p. 29).

Sin embargo, esta multiplicación no engendrada puede formar parte de un hacer humano que imite lo silvestre. Bertoni (1927, p. 456), el naturalista suizo

12 Medida de superficie equivalente a 2,4 ha.

13 Estas rueditas aluden a la forma circular de las rozas indígenas que aún en la actualidad desafían las convenciones técnicas estatales, orientadas al plantío en canteros rectilíneos que facilitan el cálculo de la cantidad de semillas y de los rendimientos. 
que habitó la región desde fines del siglo XIX, recomienda utilizar malezas rizomáticas como cubierta verde: "[son] de multiplicación muy fácil, por trocitos. Se extienden rápidamente hasta ser molestas donde no sean necesarias", y entre las que dan mejores resultados, menciona "las Kaapuerava o yerbas de santa lucía [...] que crecen en las tierras que fueron rozados", recuperando así la conexión entre la capuera y el rozado.

La mimetización con la propagación silvestre, a través del auto engendramiento de repollos y mandiocas, facilitó la alimentación de los colonos. Una colona suiza cuenta: "la Sra. Scheifler nos dio cebollas, ajos y unos repollos que hacen clones Zwacken siempre hay plantines después de cortar las cabezas" (Gallero, 2008, p. 167). Y, también: "en el otoño unos colonos me contaron que existe un tipo de repollo, llamado "repollo eterno", [...] desde el tronco nacen muchos repollos más pequeños, menos apretados. Esos tallos se pueden cortar y plantar sin raíz -y crecen y salen repollos-" (Gallero, 2014, p. 269). Con respecto a la mandioca, una colona recuerda: "Papá admiraba la planta de mandioca. [...] se arrancaba en el momento de usar, no se necesita semilla, sólo pedacitos de las ramas [...] no cuestan nada" (Gallero, 2008, p. 168).

Otro formato del proceder por imitación, lo proporcionan las afinidades entre organismos. Así, la consociación de poroto avatí y maíz pará es consignada como una práctica habitual de los guaraníes contemporáneos en Misiones (Martínez Crovetto, 1968). Bertoni (1927, p. 456), por su parte, había identificado un "poroto-maíz", "denominado kumandá avatí, porque se acostumbra a sembrarlo junto con el maíz tardío, en plantación asociada que equivale a una rotación, y es muy ventajosa para conservar la fertilidad de la tierra". La siembra jopará, ${ }^{14}$ estudiada por Boidin (2005) y observada por Schaden (1974) en poblaciones indígenas, ${ }^{15}$ inscribe el hacer humano en las afinidades naturales.

Estas asociaciones existen a contrapelo de la agricultura como mecanismo de fabricación. De este modo, los ocupantes del frente pionero, en interacción

14 Designa "la forma de plantar el avatí primero y el kumandá avatyki después, para que no sufra con la helada. [...] el kumandá se 'entremezcla' con el avati, se guía por él e invade toda la chacra; o simplemente porque hace de abono" (Boidin, 2005).

15 Entre los kaiová y los ñandeva del sur de Mato Grosso, una de las épocas de cultivo de poroto coincide con la de maíz, plantándose "de mistura" en el mismo rozado (Schaden, 1974, p. 39). 
frecuente con los rozados guaraníes, desaprueban las mezclas. Uno de ellos comenta: "El maíz de los aborígenes tiene granos de distinta clase, ellos mezclan todo, plantan todo junto. No saben mantener las variedades". Aún así, hemos observado entre estos mismos agricultores la práctica de conservar juntas, en el mismo recipiente, las semillas de las distintas especies. ${ }^{16}$

En su crítica a la asimilación de la noción de participación a desorden, Mauss (1974) señala que la tolerancia a las diferencias es reveladora de una voluntad de asemejar. Afirma: “La 'participación' no implica solo una confusión de categorías, es [...] un esfuerzo para identificarnos a las cosas y para identificar las cosas entre sí" (Mauss, 1974, p. 131, traducción propia).

La alianza entre términos heterogéneos, asemejados por identificación, compite con la filiación como mecanismo de propagación. ${ }^{17}$ Así, observando que las mudas o retoños vegetales no se localizan próximos a la planta madre, un ocupante del frente pionero refiere:

Mirá el kokú [A. edulis]! Debajo de la planta no encontrás plantitas, pero si te vas a esos pinares donde defecan las palomas, hay muchas plantitas de kokú. Igual la yerba: en el yerbal tenés mucha semilla pero no vas a ver plantitas. Necesitan el calor de la digestión de los animales

Como veremos en la última sección, la utilización a sabiendas de las afinidades entre organismos caracteriza el vínculo con la naturaleza de la agroecología en general y de la biodinámica en particular. En este sentido, los preparados de fertilización son compuestos que mezclan estiércol animal con vegetales y minerales, y que, a semejanza de la siembra asociada de maíz y poroto, reciben el apelativo jopará en una finca biodinámica de Paraguay. ${ }^{18}$

16 Sirley trae su bolsa de semillas y enumera: "Esta es de sandía, una semilla criolla que compré en Brasil y dió muy bien. Esta es melón, también de Brasil, estas de sandía enana que me dio mi vecina. Este es maíz catete amarillo, antes se hacía este maíz, este marlo viene de Campo Viera, me lo dio Inés [vecina]. Se dejó de plantar porque es de harina. Ahora plantamos otras clases porque lo que hacemos es transformar maíz en carne".

17 La naturaleza procede mediante "combinaciones que no son ni genéticas ni estructurales, interreinos, participaciones contra natura" (Deleuze; Guattari, 2004, p. 248).

18 Moringa Ygua, Piribebuy, Paraguay. 


\section{Fabricaciones}

La territorialización de la agricultura promovida por la colonización de Misiones, con la consecuente subdivisión de la tierra, alteró la simbiosis del monte y el rozado. El devenir vegetal que imita el monte -la capuera- resultó incompatible con el carácter irreversible de la domesticación controlada por los humanos. La fabricación, según la cual las cosas son constituidas mediante la trasposición racional de formas preconcebidas sobre una sustancia inerte, sustituye el tejido de materiales activos que acompaña el proceder de la naturaleza (Ingold, 2013).

Nuestra argumentación considera la naturaleza como un proceder, que da cuenta de los procesos sin afiliarlos a representaciones simbólicas. Las asociaciones se establecen por contigüidad, mediante series de identificaciones sucesivas en las que participan vegetales, animales, humanos y entidades suprasensibles. La capuera ilustra una acción de este tipo, mientras que la agricultura intensiva constituye un formato que supone la operación de la mente.

La técnica del rozado sin quemar, combinada con estrategias de conservación de la fertilidad, tales como las cubiertas verdes, ${ }^{19}$ interrumpieron la serie de progresión y regresión del monte y el rozado. El ya mencionado naturalista suizo Bertoni (1927, p. 459), encaró la racionalización de la agricultura campesina de la región recomendando "la abolición de la antigua costumbre de quemar los rozados y los despojos, y la introducción de la costumbre moderna de mantener la tierra continuamente bajo cultivo". Y, continúa:

El hecho que abunden todavía tierras de monte virgen y los buenos capuerones [...] no basta para explicar lo poco que se ara. [...] nuestra clase rural no comprende el interés actual y para el porvenir, de meter arado en esos campos, en vez de meter hacha en el monte. (Bertoni, 1927, p. 82-83).

19 De acuerdo a Bertoni (1927, p. 445), "la cubierta del suelo en las plantaciones constituye la más importante reforma moderna de la agricultura de los países calientes. A medida que avanzaban los grandes cultivos en zonas tropicales se vieron efectos negativos de escardar (deshierbe). En Malasia se la llamó: rutina tránsfuga de la agricultura europea. Se propuso como medio para combatir las mala hierbas, la cubierta verde, es decir el cultivo de plantas herbáceas útiles que cubran continuamente el suelo". 
Los ritmos vegetales y humanos fueron ordenados mediante la confección de un almanaque. Publicado en tres oportunidades (1903, 1926 y 1927), en las últimas ediciones bajo el nombre de Agenda \& Mentor agrícola. Guía del agricultor \& colono con el calendario de todos los trabajos rurales, este instrumento alcanzó una notable difusión.

El empleo del arado, reclamado por Bertoni con el fin de volver perenne la ocupación del suelo, también fue solicitado por el especialista agrícola enviado a Misiones por el gobierno nacional a principios del siglo XX, que objetó el uso generalizado del saracuá (palo cavador), considerándolo "un resabio indígena" (Yssouribehere, 1904, p. 99).

En la tarea de fabricación de naturaleza, los agricultores provenientes de Europa se sirvieron de las mismas herramientas empleadas en sus lugares de origen, confeccionadas en Misiones por algunos compatriotas. Un colono refiere: "Encargamos un arado al viejo Pohluraun, oriundo de Berlín [...] lo pagamos en cuotas" (Weyreuter, 1992, p. 84-85).

Sin embargo, el carácter inerte de la naturaleza a domesticar no fue tal. Uno de ellos relata:

Lo que significa quebrar tierra virgen solamente lo comprende alguien que lo ha hecho [...] No se puede hablar de "arar". Si se mira el trabajo hecho más bien parece que una piara de cerdos hubiera removido la tierra. Todo el suelo parece ser una raíz enmarañada. El tejido de las raíces de la tacuara, las más finas del tacuapí y las raíces de los árboles están unidas como un tejido. (Weyreuter, 1992, p. 84).

A pesar de los embates de funcionarios y especialistas contra el sistema de roza y quema, la instalación agrícola de los colonos se efectuó empleando esta práctica conocida, ahora desprovista de movilidad y capueras. Un colono suizo describe la génesis de su rozado en estos términos:

Sobre la tierra quemada quedan solamente los troncos más grandes y las ramas de los árboles. A estas un novato las querría también retirar, sin embargo un colono de la selva las deja en el suelo y planta entre medio de ellas su primer maizal en ese suelo virgen. Después de la primera cosecha los duros tallos y rastrojos del maíz, junto con los yuyos se acomodan al lado de los troncos y las ramas y se prende fuego nuevamente. Esto se sigue haciendo así y quemando 
hasta que hayan transcurrido tres años [...] al tercero o cuarto año ya se puede pasar el arado por el nuevo terreno de cultivo. A partir de ese momento se comienza con una plantación de yerba o tabaco si el colono quiere comercializar productos, o plantará pastura si se va a dedicar a la cría de ganado vacuno. (cf. Gallero, 2008, p. 34).

En otro caso, el joven colono refiere:

No teníamos la más remota idea de cómo voltear un árbol, el sr. Gluchsberg se ofreció a enseñar a mi padre lo elemental. A la mañana siguiente partieron los dos armados de hachas y machetes. [...] Después de varios días pude ayudar a despejar el rozado, que era muy pequeño. Los palos verdes no quisieron arder y hubo que cortar todo en trozos con hacha y serrucho. Todo fue amontonado en enormes pilas para quemarlo. (Weyreuter, 1992, p. 27).

Otro colono alemán relata en sus memorias:

¿Qué sabía un novato del tratamiento que había que dar a los suelos de la selva virgen que no tienen ninguna similitud con los de nuestra vieja patria? Nuestros ejemplos de colono vinieron del Brasil, donde hicieron cultivos de empobrecimiento de la tierra. Al infertilizarse un terreno, ellos se mudaban a una colonia nueva y empezaban de nuevo. Pero nosotros queríamos hacer prosperar la tierra, y no cambiarnos después de algunos años. Esto nos obligó a proceder de otra forma. Aún hoy, después de 50 años se cultiva nuestra tierra con éxito. (Müller, G., 1995, p. 29).

\section{Y, en otro caso:}

Si bien mis padres eran hijos de agricultores suizos, carecían de experiencia para la agricultura tan distinta de la europea. Papá tuvo la suerte de encontrar unos amigos entre los colonos alemán-brasileños que le enseñaron muchas cosas útiles. Por supuesto, había que creerles. Supimos de colonos suizos que no tenían la más mínima idea de cómo trabajar la tierra. Como aquel -enseñado bien por un vecino, que la mandioca se planta con las ramas- que se burló, [...] plantó la mandioca con las raíces y se pudrieron. Perdió toda la cosecha. (Gallero, 2008, p. 183). 
Es decir, la instalación de agricultores de ultramar, concebida como un modo de neutralizar la simbiosis con el monte de la agricultura nativa no pudo desligarse completamente de los procesos naturales y de las prácticas de las poblaciones indígenas. Así, un colono rememora: "El desmonte se inició con la ayuda de un Indio Tupí, quien por su trabajo les pidió la única arma que traían [...] a cambio de enseñarle a jugar al ajedrez, obtuvieron el hacha y las primeras experiencias en el monte" (Gallero, 2008, p. 188).

\section{Filiaciones: engendrar naturaleza mediante trabajo humano}

La actividad agrícola como fabricación comportó el uso duradero del suelo, privilegiando las plantas perennes ("plantas de raíz") y forzando el desplazamiento hacia los márgenes de los grupos guaraníes. La fabricación estuvo encaminada a lograr plantaciones de una sola especie, destinadas a la industria (yerba, tabaco, citrus, té). Un colono relata la formación de su yerbal, a partir de mudas adquiridas en un vivero: "saqué las plantas del cajoncito, las puse en el agujero, apreté la tierra. Así planté cien, mil, dos mil plantas. Era un placer verlos, paraditos como soldados" (Gallero, 2014, p. 162).

Asentado sobre una matriz hilemórfica, ${ }^{20}$ el proceder del colono filia la naturaleza al trabajo humano, proyectando un diseño sobre la materia. En palabras de la hija de un pionero: "verdaderos colonos, personas [...] que dedicaban íntegramente la vida a la lucha, y al trabajo [...] y lograban hacer realidad sus proyectos" (Culmey, 1998, p. 40). Metamorfosis del propio ambiente, tales como la capuera, y fenómenos derivados de la cohabitación entre organismos, significan la derrota del hacer humano basado en la fabricación. De este modo, el estudio de Eidt (1971) sobre la colonización en Misiones contiene solo una referencia a la capuera, en conexión con la calificación de suelos degradados.

La connotación negativa atribuida a los devenires vegetales que desafían el control humano esta presente en las referencias a la capuera y a los rozados guaraníes, registradas entre los ocupantes del frente pionero.

20 Del griego hyle (materia) y morfe (forma). Basada en la dicotomía entre una materia inerte a la que la mente humana le impone forma. 
Si bien los conflictos por la tierra entre paisanos guaraníes y agricultores se volvieron más intensos a fines del siglo XX, la fricción entre la colonización y el régimen móvil de uso del suelo de los grupos indígenas marca la historia del poblamiento de la provincia, teniendo como consecuencia el despojo de los territorios originarios y el arrinconamiento de las comunidades (Schiavoni, 2018).

El sentido del término capuera como antigua chacra, que inscribe en el paisaje la presencia humana, documentando la ocupación, se transformará en la noción de capuera como tierra abandonada, susceptible de apropiación para la agricultura de renta.

Un lugar común de los relatos sobre el poblamiento agrícola espontáneo es la mención a la capuera como una señal que justifica la apropiación de la tierra. Los ocupantes rememoran: "Esto era todo monte, todo capuera cuando entramos”; “Había capuerón cuando entramos. Era capuera, abandonado”; “El que vendió la mejora, según yo compré por 8 ha de potrero, pero era capuerón. Estaba abandonado".

La capuera amenaza la filiación de la naturaleza al trabajo humano. Así: "Perdieron el tabaco en la capuera. Corrió lluvioso y no se podía carpir. El tabaco ya llegó al tamaño de empezar el despunte y si la hoja está chiquita no recupera más de la capuera". Y también: "Tenía un buen comienzo, tenía vaca. Ahora la chacra está todo capuera, inçada [inços: malezas], ya no se puede vencer la capuera".

Los límites impuestos a la fabricación encarada por los colonos provendrán de la pérdida de la fertilidad del suelo. Bartolomé (1990) caracteriza en términos de agricultura intensiva las prácticas de los colonos del sur de Misiones en las primeras décadas del siglo XX. En efecto:

Una chacra típica de ese período tenía 10 ha cultivadas de un total de 25 ha [...] Sólo una y 2 hectáreas estaban en barbecho anualmente. Esto indica un desvío importante del sistema tradicional de tres campos. A pesar de que los nuevos suelos de la colonia reaccionaron bien inicialmente a ese tipo de explotación intensiva, el proceso de pérdida de fertilidad fue iniciado así y se abrieron las puertas a la erosión. (Bartolomé, 1990, p. 163, traducción propia).

El ambientalismo de fines de la década de 1970 en la provincia continúa el embate contra la agricultura de roza y quema, encarnada en la figura del 
ocupante, que propaga el poblamiento sobre las tierras fiscales del nordeste provincial. $^{21}$

Un colono suizo, considerado el primer ecologista de la provincia, junto con Bertoni, recupera el término capuera, ahora en su acepción de 'futuro monte'. En cartas, dirigidas a Misiones, escribe en el año 1982: "las capueras no se deben machetear y quemar como antes, deben tratarse como bosques" (Roth, 1987, p. 77). La quema de materia orgánica es desaprobada y calificada como "el drama de las eternas capueras". Así:

El que quiere sacar provecho de una capuera, debe estar convencido de que el fuego no es su amigo y aliado, sino su enemigo engañador. Esto, a pesar de que para un solo año la ceniza favorezca el cultivo de poroto o maíz, pero ¿qué significa en la vida de un colono o agricultor un año? (Roth, 1987, p. 77).

También Bertoni, citado en un documento oficial para pequeños productores, apela a la larga duración cuando advierte: "La ciencia dirá a nuestros campesinos que lo que están quemando con tanta pertinacia y obstinación, no son solamente los rozados, los campos, los rastrojos, sino sus futuras cosechas, su propio porvenir y el de la Nación misma" (Desarrollo..., 1998, p. 1).

En consonancia con esta ideas, una reconocida especialista en agroecología que visita la provincia a mediados de la década de 1990, vincula las prácticas de roza y quema y degradación de suelos con los derechos móviles sobre la tierra. En efecto:

Muchas veces los agricultores, principalmente los arrendatarios en agricultura itinerante o migratoria queman los pastos y las capueras. Y plantan en la ceniza rica en potasio, calcio y magnesio consiguiendo buenos resultados al principio. Sin el retorno de la materia prima, el suelo se empobrece haciendo disminuir la producción después de sucesivas quemadas. (Boletín del Programa Social Agropecuario, 1996, p. 3).

21 Concluida la colonización en la década de 1940, el acceso a pequeñas parcelas se llevará a cabo mediante la ocupación no planificada de tierras fiscales vacantes, una tendencia de larga duración en la provincia, que existió en forma simultánea a la empresa de colonización (Schiavoni, 1995). 


\section{Obras}

La adopción de la biodinámica en Misiones reanuda la conexión con la metrópoli de colonos europeos, acuciados por las consecuencias de la artificialización de la agricultura.

Tributaria de las Naturphilosophie de principios del siglo XIX, esta concepción nace en contraposición al materialismo y a la imagen mecánica de los fenómenos de la vida. Formulada como un método a mediados de la década de 1920, en el momento en el que la agronomía está dominada por la química inorgánica de Julius Liebig y el papel determinante de los elementos minerales mayores en la fertilidad del suelo (nitrógeno, fósforo, potasio y calcio), la biodinámica rescata el "obrar de la naturaleza", entendiendo como tal el efecto de los planetas y la acción de los minerales presentes en pequeñas cantidades en los seres vivos, soslayados por la química inorgánica. En este esquema, los humanos desempeñan el rol de mediadores en los intercambios cósmicos, ayudando a las plantas a recibir y acumular influencias. ${ }^{22}$ Entronca así con la filosofía de la naturaleza de Goethe y con ciertas prácticas campesinas tradicionales. ${ }^{23}$

El relato biográfico de un colono de Misiones refiere la realización de un viaje a su lugar de origen con el fin de recabar asesoramiento acerca de la erosión, tomando contacto con la agricultura biológico dinámica. Así:

En 1938, Alberto y Gritli realizaron un corto viaje a Suiza. Allí una de sus preocupaciones fue cómo tratar los yerbales en el futuro, para lo cual visitó a su antiguo maestro, "el Señor von Meyenburg con quien hablé sobre los problemas del suelo. Fui a Dornach, al Goetheanum [...] miré los libros allí expuestos. Conocí a la señorita Riese, la directora de Agricultura Biológica-Dinámica, y compré el libro de Ehrenfried Pfeiffer La fertilidad de la tierra". (Gallero, 2013, p. 65).

22 "El hombre se ha emancipado casi totalmente del cosmos, la vida animal algo menos, pero lo vegetal se halla sumido en alto grado en la vida natural [...] Y no habrá comprensión alguna [...] al menos que se considere que todo lo que está sobre la tierra es un reflejo de lo que ocurre en el cosmos" (Steiner, 1988, p. 39).

23 "La frase que extraigo aquí de la investigación antroposófica: ‘En la economía de la Naturaleza, la planta da y el animal toma' fue una vez [...] familiar dentro de un conocimiento clarividente instintivo de la naturaleza. Hay cosas que se mantuvieron vigentes en hombres especialmente sensitivos [...] Justamente en Goethe hallan un repetido uso de esta frase: 'En la naturaleza, todo vive de dar y tomar"' (Steiner, 1988, p. 219). 
Descola (2012) señala el carácter antropocéntrico de las filosofías ambientalistas, en las que el reconocimiento de las relaciones de interdependencia entre los componentes orgánicos y abióticos no resigna la centralidad de los humanos en la conservación del equilibrio.

A semejanza de las ontologías analogistas, la biodinámica fracciona lo real en una multiplicidad de esencias vinculadas a través de una red de analogías establecidas por los humanos mediante asociaciones no basadas en propiedades superficiales, en las que lo semejante produce lo semejante y la causa es similar al efecto. ${ }^{24}$

De manera similar al proceder naturalcultural analizado en la primera sección, los procesos de simbiosis y afinidades entre especies son valorados por la agroecología a través de la noción de plantas compañeras. La referencia a propiedades y entidades suprasensibles ("la espiritualidad") establece un lazo entre la biodinámica y la cosmología guaraní, en la que el obrar supone entablar relaciones con entidades suprasensibles como los dueños de las plantas, de los animales y de los elementos del paisaje. Sin embargo, en el caso de la agricultura biodinámica, son los humanos los que asumen la coordinación.

La actividad agrícola es encarada como un arte, inserto en una naturaleza ensanchada, que coincide con el cosmos. La representante de una Cooperativa biodinámica de Misiones describe así esta forma de producción: "se trabaja con las fuerzas de la naturaleza que están disponibles para tal o cual proceso" (Rotela, 2018, p. 12). En contraste con la fabricación, se trata de una actividad de pilotaje (Larrere, 2002), sensible al contexto que contempla la creación constante de técnicas, dando nacimiento a una "agricultura de autor", basada en obras y no en mecanismos. ${ }^{25}$

24 Las malas hierbas, cuya reproducción está fuertemente influenciada por la luna, se combaten juntando las semillas, quemándolas y esparciendo las cenizas en el campo de cultivo, ya que "tenemos concentrada en la ceniza la fuerza opuesta a la que se desarrolla por la atracción de la fuerzas lunares" (Steiner, 1988, p. 175). Del mismo modo, para exterminar al ratón de campo es menester incinerar un pellejo obtenido cuando el planeta Venus está en el signo de Escorpio y esparcir las cenizas en el campo: "En lo destruido por el fuego quedará ahora una fuerza negativa con respecto a la fuerza de reproducción del ratón de campo" (Steiner, 1988, p. 179).

25 El biofertilizante "supermagro", difundido por la RAOM [Red de Agricultura Orgánica de Misiones] e incluido en el Catálogo de tecnologías para pequeños productores de Argentina, lleva el nombre de su autor: fue creado en Brasil por Edelvino Magro para transformar en orgánicos sus manzanares. La versión que se utiliza en Misiones se basa en un trabajo de adaptación llevado a cabo por el ingeniero Piamonte del Instituto Biodinámico de Desarrollo Rural, Botucatu San Pablo, Brasil. 
Así, el "producir imitando a la naturaleza" deviene un imperativo moral para algunos colonos de Misiones. Uno de ellos relata:

No se necesita destruir para producir [...] yo estaba carpiendo mucho. [...] He visto la erosión en la casa de los vecinos que pasaban el tractor 5 a 6 veces porque el arado no tenía filo [...] pulvericé también por mi inconciencia [...] Y después dejé todo [...] uno ve ahora con este manejo de respeto a la naturaleza que la tierra tiene vida [...] Por eso ahora trato de producir imitando a la naturaleza. (Boletín del Programa Social Agropecuario, 1996, p. 5).

\section{Alianzas y reafiliaciones: el trabajo humano asociado a la naturaleza}

La apropiación de la agricultura biodinámica por parte de colonos de Misiones y del sur de Brasil ocurre en conexión con problemas productivos, y no a través de un compromiso con la filosofía de Steiner ${ }^{26}$ Se traduce en el uso de instrumentos, tales como el calendario lunar y los compuestos de fertilización.

La sistematización de la influencia de la luna sobre el crecimiento de raíces y hojas, ${ }^{27}$ proporciona una dimensión cósmica a los procesos naturales, retomando un savoir faire extendido de los agricultores de Misiones, también presente en la agricultura indígena de la región. ${ }^{28}$ Un colono de Misiones relata en sus memorias:

La influencia de la luna en la vida de las plantas es enorme [...] Después de una observación de muchos años, todos mis trabajos se reparten según las fases lunares [...] no es aconsejable replantar en luna nueva, pues la planta muere o

26 Volkmann (2011) refiere un itinerario de este tipo en el caso de Rio Grande do Sul, donde la agencia alemana de cooperación jugó un rol clave vinculando a la agricultura biodinámica a productores con suelos degradados. Una trayectoria similar es descripta por Pinheiro et al. (2018).

27 De acuerdo a la biodinámica, la menor individuación de las plantas con respecto al cosmos hace que su actividad reproductiva se encuentre sujeta a la influencia de la luna. De ese modo: “La influencia del cosmos sobre la tierra a través de la luna se ejerce en luna llena. Se lograría algo importante si se estudiara hasta donde se puede llegar utilizando la Luna, por ejemplo, en lo concerniente a la actividad de la semilla cuando la siembra, como lo han hecho desde antiguo los hindúes hasta entrado el siglo XX" (Steiner, 1988, p. 173).

28 En efecto, las fases de la luna regulan la siembra de los grupos guaraníes (no se siembra en luna nueva sino en menguante) y el inicio del calendario agrícola está fijado por la aparición de las Pléyades o eichu (abejas). 
prende con dificultad. Los mejores éxitos con el replante de árboles se logran en luna llena [...] En ese tiempo también siembro todo lo demás. Las malezas se destruyen en tiempo de luna nueva. La mejor época para rozados nuevos es quemarlos 3 días después de luna nueva [...] Resumiendo, con luna creciente se labra la tierra y en la menguante se siembre y planta [...] Como colono, unido siempre con la naturaleza, observo las cosas diferente de quien vive en el pueblo. (Müller, G., 1995, p. 34-35).

Del mismo modo, un ocupante del frente pionero reconoce la influencia lunar a propósito del cultivo de tabaco, señalando: "El instructor [de la empresa] dice que el tabaco es la tierra y punto. Pero es cósmico: no hay que despuntar con creciente. También el maíz, si plantás con luna nueva crece demasiado, hay que plantar en creciente". Otra agricultora ocupante refiere: "El suegro se guiaba mucho por la luna: todo lo que va arriba de la tierra hay que plantar en creciente y lo que va abajo en menguante".

A su vez, el problema más acuciante de la agricultura colona que es la pérdida de fertilidad del suelo recibe una solución natural de parte de la biodinámica. El conocimiento de sustancias que actúan en pequeñas dosis (micronutrientes) y el manejo de reacciones producidas por los seres vivos (fermentaciones, captación orgánica de nitrógeno, etc.) están en el origen de los compuestos o biofertilizantes que distinguen esta práctica.

La mirada multiespecie también está presente en el enfoque de sistemas agroforestales, que se difunde en Misiones a principios de la década de 1990, con el fin de combatir el desmonte y la erosión.

El fundamento de esta tecnología apela a las asociaciones entre organismos, tratando de "optimizar interacciones positivas entre componentes y entre éstos con el ambiente físico para obtener mayor productividad total, más diversificada y más rentable de modo perdurable" (Salvador, 1993, p. 8). La innovación permitirá contrarrestar la "perjudicial agricultura migratoria que produjo la lenta desaparición de relictos de la selva misionera" y "evita la tentación de anuales: soja, maíz". La genealogía de esta innovación se remonta a los colonos. En efecto, el ingeniero forestal que la difunde afirma:

A este panorama trágico de degradación debemos oponerle la acción del colono, que también vislumbró la necesidad de planificar y producir en su chacra 
cultivos alternativos, organizando asociaciones de árboles, cultivos anuales y perennes, pasturas y otros, naciendo así el concepto de cultivos asociados con árboles (yerba y Pino Paraná, por ej.). (Salvador, 1993, p. 8).

La "agroforestería”, entonces, "es una palabra nueva que designa la vieja práctica de cultivar especies leñosas junto a cultivos agrícolas y/o ganado en una misma tierra" (Araucaria Producciones, 1994, p. 7). La utilización de procesos llevados a cabo por los seres vivos que habitan el monte está en la base de esta innovación. En una nota dirigida a los agricultores "como investigadores de los sistemas agroforestales" se menciona que: "En las raíces de árboles leguminosos se produce el fenómeno de fijación simbiótica de nitrógeno y otras asociaciones (mycorrhizas) que favorecen la absorción de nutrientes del suelo" (Lacorte, 1991, p. 7).

La difusión del enfoque de los sistemas agroforestales en Misiones adjudica al componente forestal el rol decisivo en el mantenimiento de la fertilidad. El documento oficial sobre desarrollo sostenible para pequeños productores ya citado, recuerda que: "El mejor plaguicida es el monte con todas sus plantas y animales", y recomienda: "Recuperar las capueras plantando en ellas las especies de árboles nativos de mayor valor económico".

Así, esta reafiliación de la agricultura a la naturaleza estabiliza el significado de la capuera sólo en su acepción de monte futuro. La simbiosis del monte y el rozado es absorbida por uno de sus polos. Como concluye en sus memorias uno de los colonos: "A veces me pongo a pensar y llego a la conclusión de que esta tierra de Misiones, para lo que está hecha es para ser selva y no para todas estas explotaciones que, por una u otra razón, a la larga terminan en un fracaso" (Gallero, 2008, p. 154).

\section{Conclusiones}

El constructivismo, y las perspectivas racionalistas en general, colocan en la mente humana el motor de la acción. La imitación queda relegada a un momento anterior, previo a la identificación de un mecanismo o a la elaboración de una representación simbólica. Reñida con la invención, la imitación corresponde a la formulación de modelos miméticos, basados en semejanzas 
superficiales. Así, Bachelard, citado por Bourdieu, Chamboredon y Passeron (1975), afirmaba que la máquina de coser se inventó sólo cuando se dejó de imitar los movimientos de la costurera.

En cambio, el argumento que desarrollamos en este artículo asigna un papel decisivo a la materialidad no procesada simbólicamente en la acción cultural. Inmersos en el ambiente, en conexión con otros organismos, seguimos algunos cursos de acción, imitando el hacer de los no humanos. La domesticación deja de ser un diseño de la mente para convertirse en un proceso emergente de la cohabitación entre especies.

A través de una reflexión arraigada en la provincia de Misiones, nuestro artículo recorre la secuencia de operaciones que va desde la imitación y el acompañamiento de los devenires vegetales por parte de los humanos, pasando por la imposición de un diseño sobre la materia inerte -la agricultura como fabricación de naturaleza-, hasta la transformación de los procesos naturales en objetos técnicos, vía la agroecología y la biodinámica.

Entrelazamos en nuestra argumentación las acciones sobre el ambiente vinculadas a las poblaciones originarias y a colonos inmigrantes, describiendo fricciones y convergencias en torno a la noción de capuera.

La significación subrepresentativa revierte la descalificación de la imitación en la producción, ya que le atribuye la capacidad de propagación de flujos. Mediante mezclas y participaciones, este proceder extiende la acción a partir de los propios elementos de un dominio, sin recurrir a un principio externo. En el caso que nos ocupa, lo que se propaga mediante la imitación es la serie de progresión y regresión del monte y el rozado, fundada en un vínculo de continuidad entre naturaleza y cultura y expresada en la condición híbrida de las comunidades vegetales resultantes, tales como la capuera.

La actividad agrícola como fabricación, a su vez, segmenta esta continuidad, estableciendo una oposición a partir de la cuál filia la materia a las representaciones simbólicas. Mediante la identificación de mecanismos, con efectos repetidos y previsibles, produce multiplicidad a través de la reproducción por aplicación de un molde. Desde esta perspectiva maquinal de clonación, las acciones conjuntas de vegetales y humanos representan abdicaciones de los humanos. La noción de la capuera como un espacio abandonado e improductivo, desconociendo la actividad de los vegetales y las inscripciones humanas pretéritas, resulta compatible con este esquema. 
Finalmente, la inscripción de lo técnico en lo orgánico, a partir de la consideración de la tecnología como un fenómeno biológico general, y no exclusivamente como una operación intelectual, constituye una conjunción de las fuerzas de la naturaleza y las fuerzas de la cultura. La orientación hacia lo múltiple y repetitivo es sustituida por la obra creadora de humanos que duplican la naturaleza utilizando las semejanzas, contagios y asociaciones entre organismos con fines de producción. Esta copia detiene la serie de progresión y regresión del monte y el rozado, asignando al primero una primacía distintiva, conservando el significado de la capuera sólo en su acepción de futuro monte.

En síntesis, imitar a la naturaleza no consistiría en replicar un producto (el monte, la selva) sino adoptar un proceder, mimetizándose con las afinidades y devenires vegetales.

\section{Referencias}

AMBROSETTI, J. Viaje a las Misiones argentinas y brasileras por el Alto Uruguay. La Plata: Talleres de Publicaciones del Museo, 1892.

ARAUCARIA PRODUCCIONES. Tecnología para ganar. Diversificación con todo y para todos. Sistemas agroforestales: Una solución posible. Un ejemplo reciente: proyecto de INTA Cerro Azul. El Territorio, Posadas, p. 7, 29 jul. 1994.

BARTOLOMÉ, L. The colonos of Apóstoles: adaptative strategy and ethnicity in a Polish-Ukrainian settlement in Northeast Argentina. New York: AMS, 1990.

BERTONI, M. Agenda y mentor agrícola: guía del agricultor y colono. Puerto Bertoni: Ediciones Ex Sylvis, 1927.

BOIDIN, C. Jopará? Jehe'a?. El mestizaje de las palabras, de las plantas y de los cuerpos en Paraguay. Nuevo Mundo, Mundos Nuevos, Bibliothèque des Auteurs du Centre, 2005. Disponible en: https://journals.openedition.org/nuevomundo/598. Acceso: 10 dic. 2018.

BOLETÍN DEL PROGRAMA SOCIAL AGROPECUARIO. Eldorado, n. 9, 1996.

BOURDIEU, P.; CHAMBOREDON, C.; PASSERON, J. C. El oficio del sociólogo. Buenos Ares: Siglo XXI, 1975.

BURMEISTER, C. Memoria sobre el Territorio de Misiones. Buenos Aires: Peuser, 1899. 
CADOGAN, L. Extranjero, campesino y científico: memorias. Asunción: Centro de Estudios Antropológicos de la Universidad Católica, 1990.

CARNEIRO DA CUNHA, M. Cultura com aspas e outros ensaios. São Paulo: Cosac Naify, 2009.

CEBOLLA BADIE, M. Colonos y paisanos. Indios y Jurua Kuery. Relaciones interétnicas y representaciones sociales en Colonia La Flor-Misiones. Avá, Posadas, n. 2, p. 129-142, 2000.

CONKLIN, H. An ethnoecological approach to shifting agriculture. Transactions of the New York Academy of Sciences, New York, v. 17, n. 2, p. 133-142, 1954.

CRIVOS, M. et al. Pathways as 'signatures in landscape': toward an ethnography of mobility among the Mbya-Guarani (Northeastern Argentina). Journal of Ethnobiology and Ethnomedicine, 2007. Disponible en: https://ethnobiomed.biomedcentral. com/articles/10.1186/1746-4269-3-2. Acceso: 10 dic. 2018.

CULMEY, T. La hija del pionero. Posadas: Editorial Universitaria de Misiones, 1998.

DELEUZE, G.; GUATTARI, F. Mil mesetas: capitalismo y esquizofrenia. Valencia: Pretextos, 2004.

DESARROLLO sostenible de pequeños productores rurales de Misiones. Buenos Aires: Ministerio de Salud Pública: Ministerio de Asuntos Agrarios: Ministerio de Ecología y Recursos Renovables, 1998.

DESCOLA, P. Más allá de naturaleza y cultura. Buenos Aires: Amorrortu, 2012.

EIDT, R. Pioneer settlement in Northeast Argentina. Madison: University of Wisconsin Press, 1971.

FERRERO, B. La lucha contra la selva. Percepciones y usos de la naturaleza entre los colonos misioneros. Avá, n. 15, p. 145-159, 2009.

GALLERO, C. (comp.). El llamado del oro verde. Buenos Aires: Araucaria, 2008.

GALLERO, C. Entre la selva paranaense y el cultivo de la yerba mate: el aporte de Alberto Roth (1901-1985) a la historia ambiental de Misiones (Argentina). Revista Latino-Americana de História, v. 2, n. 8, p. 53-74, 2013.

GALLERO, C. (ed.). Querida Misiones, hermosa!: a través de las memorias de Alberto Roth. Buenos Aires: Araucaria, 2014.

GEERTZ, C. Agricultural involution: the processes of ecological change in Indonesia. Berkeley: University of California Press, 1970. 
GUASCH, A.; ORTIZ, D. Diccionario castellano-guaraní - guaraní-castellano. Novena edición. Asunción: CEPAG, 1993.

HAUDRICOURT, A. Domestication des animaux, culture des plantes et traitement d’autrui. L'Homme, Paris, t. 2, n. 1, p. 40-50, 1962.

INGOLD, T. Marcher avec les dragons. Bruxelles: Zones Sensibles, 2013.

JOVER PERALTA, A.; OSUNA, T. Diccionario guaraní-español y español-guaraní. Buenos Aires: Tupá, 1950.

KIRKSEY, E.; HELMREICH, S. The emergence of multispecies ethnography. Cultural Anthropology, Washington, v. 25, n. 4, p. 545-576, 2010.

KOHN, E. How forests think: toward an anthropology beyond the human. Berkeley: University of California Press, 2013.

LACORTE, S. El agricultor como investigador en los sistemas agroforestales. El Territorio, Posadas, p. 7, 24 nov. 1991.

LARRERE, R. Agriculture: artificialisation ou manipulations de la nature?. Cosmopolitiques, Rennes, n. 1, p. 158-173, 2002.

LÉVI-STRAUSS, C. La pensée sauvage. Paris: Plon, 1962.

LÉVY-BRUHL, L. La mentalité primitive. Paris: Presses Universitaires de France, 1947. MARTÍNEZ CROVETTO, R. Esquema fitogeográfico de la provincia de Misiones. Bonplandia, Corrientes, t. 1, n. 3, p. 171-223, 1963.

MARTÍNEZ CROVETTO, R. Notas sobre la agricultura de los indios guaraníes de Misiones (República Argentina). Etnobiológica, Corrientes, n. 10, p. 1-11, 1968.

MAUSS, M. Oeuvres: tome 2: représentations collectives et diversité des civilisations. Paris: Minuit, 1974.

MICHAELIS. Dicionário prático da língua portuguesa. São Paulo: Melhoramentos, 1987.

MÜLLER, F. Etnografía de los Guaraní del Alto Paraná. Rosario: Escuela de Artes Gráficas del Colegio Salesiano San José, 1989.

MÜLLER, G. Memorias de Heiner Müller: pionero de Montecarlo. Posadas: Editorial Universitaria, 1995.

MUSUMECI, L. O mito da terra liberta: colonização "espontânea", campesinato e patronagem na Amazônia Oriental. São Paulo: Vértice, 1988. 
NAUJORKS, A. Infierno verde Alto Paraná: memorias de un pionero de Montecarlo. Posadas: Editorial Universitaria, 1995.

NIKLISON, J. Vida y trabajo en el Alto Paraná en 1914. Resistencia: Instituto de Investigaciones Geohistóricas, 2009.

PEYRET, A. Cartas sobre Misiones. Buenos Aires: Imprenta de la Tribuna Nacional, 1881.

PINHEIRO, S. P. et al. Tramas agroecológicas na colônia de Pelotas. Anuário Antropológico, Brasília, v. 43, n. 1, p. 93-122, 2018.

QUEIREL, J. Misiones. Buenos Aires: Taller Tipográfico de la Penitenciaría Nacional, 1897.

RENGGER, J. Viaje al Paraguay en los años 1818 a 1826. Asunción: Tiempo de Historia, 2010.

ROTELA, M. Productores coparon la plaza 9 de Julio. El Territorio, Posadas, p. 12, 17 oct. 2018.

ROTH, A. Naturaleza y hombre. Posadas: Montoya, 1987.

RUIZ DE MONTOYA, A. El tesoro de la lengua guaraní. Madrid: Juan Sánchez, 1639.

SALVADOR, A. “Tecnología para ganar”. Técnica, económica y ecológicamente convenientes. Sistemas agroforestales. Primera Jornada Regional. El Territorio, Posadas, p. 8, 12 dic. 1993.

SCHADEN, E. Aspectos fundamentais da cultura guarani. São Paulo: Editora da Universidade de São Paulo, 1974.

SCHIAVONI, G. Colonos y ocupantes: parentesco, reciprocidad diferenciación social en la frontera agraria de Misiones. Posadas: Editorial Universitaria de Misiones, 1995.

SCHIAVONI, G. Habitar y medir el territorio. Los vínculos con la tierra de colonos, ocupantes y guaraníes en Misiones. Corpus, Mendoza, v. 8, n. 1, 2018.

STAMPELLA, P. Historia local de naranja amarga (citrus aurantium rutaceae) del Viejo Mundo asilvestrada en el corredor de las antiguas misiones jesuíticas de la provincia de Misiones (Argentina) desde una perspectiva interdisciplinaria. 2015. Tesis (Doctorado en Biología) - Universidad Nacional de La Plata, La Plata, 2015.

STEINER, R. Curso sobre agricultura biológico dinámica. Madrid, 1988.

TSING, A. L. Friction: an ethnography of global connection. Princeton: Princeton University Press, 2005. 
VAN DOOREN, T.; KIRKSEY, E.; MÜNSTER, U. Estudos multiespécies: cultivando artes de atentividade. ClimaCom, Campinas, ano 3, n. 7, p. 39-66, 2016.

VOLKMANN, P. Práticas organizacionais na produção agrícola biodinámica. 2011. Dissertação (Mestrado em Administração) - Escola de Administração, Universidade Federal do Rio Grande do Sul, Porto Alegre, 2011.

WEYREUTER, H. Ardua fue la lucha: destino de los colonos alemanes en la selva. Posadas: Editorial Universitaria, 1992.

WILDE, G. Imaginarios contrapuestos de la selva misionera. Una exploración por el relato oficial y las representaciones indígenas sobre el ambiente. In: ALVARADO, G. et al. Gestión ambiental y conflicto social en América Latina. Buenos Aires: Clacso, 2008. p. 193-225.

YSSOURIBEHERE, P. Investigación agrícola en el territorio de Misiones. Buenos Aires: Compañía Sud-Americana de Billetes de Banco, 1904. (Anales del Ministerio de Agricultura, v. 1, n. 9).

Recebido: 31/01/2019 Aceito: 24/06/2019 | Received: 1/31/2019 Accepted:6/24/2019 